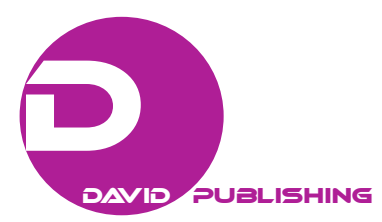

\title{
Using the Technology Acceptance Model to Analyze the Learning Outcome of Open Education Resources
}

\author{
Hsien-sheng Hsiao \\ National Taiwan Normal University, Taiwan \\ Chinese Language and Technology Center, National Taiwan Normal University, Taiwan \\ Institute for Research Excellence in Learning Sciences, National Taiwan Normal University, Taiwan \\ Pei-wun Wang, Shao-yu Lu \\ National Taiwan Normal University, Taiwan
}

\begin{abstract}
Along with the development of information and communications technology, open educational resources were widely applied in training usage. The use of these resources facilitates the access to knowledge by enabling learners to transcend time and space. In this way, learners are able to obtain new knowledge more actively and efficiently than before. Using Technology Acceptance Model (TAM) as the theoretical foundation, this study aims to explore the learning outcome of using open educational resources with the perceived convenience as the external variable. In this study, the open educational resources were defined as online courses on the Open Course Ware (OCW) and Massive Open Online Courses (MOOCs), on which the learners choose courses themselves and study without the impact from people, matters, time, space, and things with the help of the Internet. To achieve the objectives of the study, the researchers conducted a survey with the participants who had already used the open educational resources. In total, 124 valid samples were collected. The Partial Least Squares (PLS) statistical method was used to carry out the analysis. Overall, the model of this study has good prediction and explanatory power. After the data analysis, the study found that the perceived convenience exerts a positive impact on the use of the open educational resources. In addition, among the four TAM variables, the perceived usefulness does not exert a significant impact on the behavioral intention to use, but the other three TAM variables all have a significant impact on the behavioral intention.
\end{abstract}

Keywords: Technology Acceptance Model (TAM), perceived convenience, open educational resources, learning outcome

Acknowledgements: This work was financially supported by the "Institute for Research Excellence in Learning Sciences” and “Chinese Language and Technology Center” of National Taiwan Normal University (NTNU) from The Featured Areas Research Center Program within the framework of the Higher Education Sprout Project by the Ministry of Education (MOE) in Taiwan, and sponsored by the Ministry of Science and Technology, Taiwan, R.O.C. under Grant No. MOST 105-2511-S-003-049-MY3, 106-2511-S-003-019-MY3, 106-2622-S-003-002-CC2, 106-2511-S-003-049-MY3, 107-2622-S-003-001-CC2, 107-2511-H-003-0 46-MY3.

Hsien-sheng Hsiao, professor, Department of Technology Application and Human Resource Development; Chinese Language and Technology Center; Institute for Research Excellence in Learning Sciences, National Taiwan Normal University, Taiwan.

Pei-wun Wang, master, Department of Technology Application and Human Resource Development, National Taiwan Normal University, Taiwan.

Shao-yu Lu, master student, Department of Technology Application and Human Resource Development, National Taiwan Normal University, Taiwan.

Correspondence concerning this article should be addressed to Shao-yu Lu, Department of Technology Application and Human Resource Development, National Taiwan Normal University, No.162, He-ping East Road Section 1,Taipei City 10610, Taiwan. 


\section{Research Background and Motivation}

Along with the rapid development of the Internet, learning traits and styles are undergoing transformation. Learning can be underway not necessarily through a specific channel like before (Peng, 2015). The Open Course Ware (OCW) is to digitalize quality educational resources, lecture notes, and references and so forth. After that, the digitalized courses are systematically proposed online. In this way, learners can equally enjoy the right to education. With the continuous spirit of sharing their development, the Massive Open Online Courses (MOOCs) came into being, providing a learning experience similar to the one that a student experiences in physical classrooms. The MOOCs provide a new kind of online education mode offering courses that are not limited by the number of students enrolled in a class as long as one has a computer connected to the Internet, the learners can take the course anytime and anywhere. Due to the characteristic of the Internet, the learning can transcend time and space (Hsu, Ou-Yang, \& Yin, 2016). Learners take the same class with various motivations, for which some of them need to adopt self-regulated learning strategies to cope with non-customized teaching and keep up with the course schedule (Alario-Hoyos, Estevez-Ayres, Kloos, Fernandez-Panadero, \& Perez-Sanagustin, 2017). However, the benefits of the open educational resources and the influences on the learning outcome are hand to verify.

Davis proposed the Technology Acceptance Model (TAM) in 1989, which was used to explain and predict the determining factor that influences the users' acceptance of the information technology and to which degree they accept it. The model was widely verified and used in the industry and the academia, and large amount of relevant researches used this model (Agarwal \& Karahanna, 2000; Henderson \& Divett, 2003; Pai \& Huang, 2011). The model was utilized by self-report inventories. Even though this way cannot measure the use of the model precisely, the outcome of the model can be used as a relative index (Legris, Ingham, \& Collerette, 2003).

Yoon and Kim (2007) incorporated perceived convenience into the TAM as an external variable when conducting relevant researches. The researches outcome has shown that perceived convenience exerted an impacted on the variables of the acceptance of the wireless local area network. Sachez and Hueros (2010) pointed out that a digitalized learning environment can help learners transcend time and space when they are studying, which promotes meaningful learning by making learning flexible and convenient. Hsu (2017) also found that perceived convenience positively influences learners' willingness to use a uniform education platform. Therefore, this study aimed to use the perceived convenience as the external variable of the TAM, to predict the learning outcome of open educational resources.

The learning outcomes can be divided into three domains, namely cognitive, affective, and psychomotor domains (Bloom \& Krathwohl, 1956). Tough (1982) pointed out that the learning motivation and outcome can be interpreted with their learning satisfaction. Learning satisfaction is about a feeling or attitude towards learning activities. In this aspect, learning satisfaction can be used as an indicator that measures the learning outcome. Cheng and Chen (2016) found that the E-learning mode of education is considerably conducive to the improvement of students' learning attitude and outcome by the digital mode of teaching with MOOCs.

Based on the above mentioned, this research aimed to study the learning outcome of the open educational resources adopted by using the perceived convenience as the external variable of the TAM. In this study, an in-depth analysis was proposed to determine the effective of the online courses. Moreover, the perceived learning outcome after the use of the open educational resources was also studied. The analyzed data from the 
study can be used as reference for future designing of online curriculum.

\section{Literature Review}

\section{Open Educational Resources}

In the past, the channel to acquire knowledge was limited to the guidance of teachers and scholars. However, with the rapid development of online resources, learning patterns and traits have been gradually adapting in way that they no longer depend on the specific channel (Peng, 2015). The Knowledge Sharing Program, open courses, proposed by Massachusetts Institute of Technology (MIT) in 1999, provided a wide range of knowledge from across the world based on the concept of sharing. High-quality educational resources, lecture notes, and references have been digitized and made into open-ended courses. Then, the courses are systematically made available online. In this way, all different kinds of learners can equally enjoy the right to education. In 2002, Open Course Ware Consortium (OCWC) was established which makes learning transcend borders.

The New Media Consortiun (NMC) pointed out that an open content would thrive in the coming year and would exert a huge impact on the world. According to the statistics from the website of the MIT Open Courses in 2006 and 2011, users of this open course website accounted for the largest number of users in North America (33.4\%) followed by East Asia (22.1\%). In East Asia, most users came from the Chinese community, showing a demand for these open courses even in Asia (MIT Open Course Ware, 2006; 2011; Lee, Lin, \& Bonk, 2007).

Under the continuous development of Open Course Ware (OCW), Massive Open Online Courses (MOOCs) were born in 2012. The MOOCs provide everyone an opportunity to receive higher education and provide learning experience like physical classrooms. Because of this achievement, the New York Times described 2012 as the first year of MOOCs (Ho, 2013). MOOCs employ a new online teaching mode, and hence, there is no limit on the number of students who can take the course at the same time. The users only need a computer with access to the Internet to learn anywhere and anytime. Because of the characteristics of the Internet, the users can transcend time and space (Hsu, Ou-Yang, \& Yin, 2016). The motivations of learners to take courses are diverse. Some users need to adopt self-regulating learning strategies to cope with the lack of personalized counseling and follow-up courses (Alario-Hoyos, Estevez-Ayres, Kloos, Fernandez-Panadero, \& Perez-Sanagustin, 2017).

In the recent years, the rapid development of information and communications has not only changed people's lifestyles, but also has brought more ways of learning. In addition to traditional physical classrooms, online or digital learning has become an important tool in acquiring knowledge. The open educational resources explored in this study use the existing online open-ended courses to break the traditional classroom framework. Learners can effectively acquire knowledge when and where it is convenient for them. In this way, they form a flexible and efficient learning model.

\section{Technology Acceptance Model}

The Technology Acceptance Model (TAM) (Davis, 1989) was based on the Theory of Reasoned Action. The TAM has been modified by combining with Expectancy Theory and Self-Efficacy Theory to explain the determinants of users' access to information technology and predict to which extent the determinants influence their access. The TAM simplifies the Theory of Reasoned Action. The external variables replace behavioral beliefs, behavioral results, normative beliefs, and motivation to comply. When information technology is dealt 
with, the use of "perceived usefulness" and "perceived ease of use" is more effective to explain users' acceptance of information technology. Therefore, the TAM was developed, and the relationships between the various constructs are as follows (Figure 1).

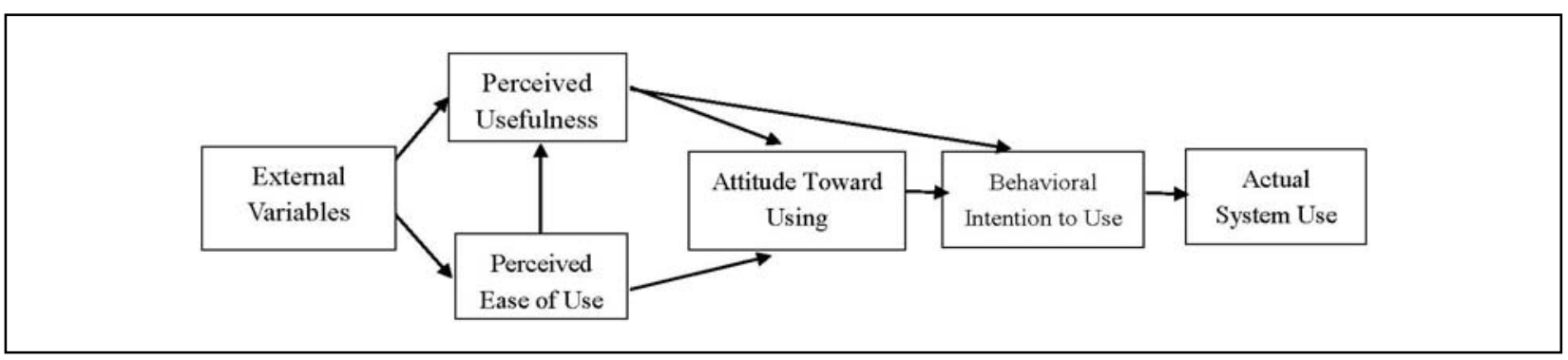

Figure 1. Technology acceptance model (Davis, 1989).

The definitions of the TAM constructs are as follows (Table 1).

Table 1

Definition of the Variables of the Technology Acceptance Model

\begin{tabular}{ll}
\hline Variable & Definition \\
\hline External variables & $\begin{array}{l}\text { The external variables that may affect the perceived usefulness and perceived ease of use } \\
\text { among users of a specific system }\end{array}$ \\
\hline Perceived usefulness & $\begin{array}{l}\text { The extent to which individuals believe that the use of a specific system can improve their } \\
\text { learning outcome }\end{array}$ \\
\hline Perceived ease of use & The extent to which individuals think how easy the operation of a specific system is \\
\hline Attitude toward usage & The positive and negative feelings individuals produce when they perform a specific action \\
\hline Behavioral intention to use & The subjective probability that individuals perform a specific action \\
\hline Actual system use & The actual system use of individuals \\
\hline
\end{tabular}

The TAM used the self-reported scale to understand the actual system use. Although the self-reported scale cannot accurately measure the actual system function, the obtained results can be used as a relative index of its actual system use (Legris et al., 2003). Conducting related researches requires a careful selection of external variables because these variables do not only influence perceived usefulness and perceived ease of use greatly, but also the actual system use (Legris et al., 2003; Burton-Jones \& Hubona, 2006). Sachez and Hueros (2010) pointed out that digital learning environments can help teaching systems transcend time and space, promote meaningful learning, and provide flexibility and convenience. Sachez and Hueros (2010) further pointed out that perceived convenience will be regarded as a key determinant of users' accepting and utilizing the information technology. Moreover, perceived ease of use positively affects perceived usefulness, and perceived convenience positively affects perceived usefulness.

Based on this model, this study proposes a TAM with perceived convenience, perceived usefulness, perceived ease of use, the attitude toward using, and behavioral intention to use as external variables which explain the extent of the acceptance of open educational resources and verify the relationship between the variables.

\section{Learning Outcome}

Learning refers to the process of causing persistent changes in human behaviors through certain activities or experiences (Chang \& Lin, 1981). Hsiao (2011) believed that the learning outcomes are the extent to which learners achieve their goals in the learning process. Teachers adopt scientific methods and tools to assess 
learning outcomes to understand learners' changes in knowledge, skills, and attitudes. The results from these processes and tools will be used as the reference for the improvement of teaching quality or curriculum design.

Tough (1982) pointed out that the motivation and results of students' participation in learning activities can be explained by learning satisfaction, which is a feeling or attitude towards learning activities. Therefore, learning satisfaction can be an index to measure learning outcomes. Baldwin and Ford (1988) found that most researchers evaluate using a self-assessment when measuring learners' behavioral changes after learning. In terms of the research related to the information technology, Huang, Liu, and Yan (2010) studied the impact of interactive whiteboards incorporated into innovative collaborative learning models on the learning outcomes and motivations of pupils in mathematics. It is found that it has significantly improved the learning outcomes and learning motivations of the pupils. The digital learning mode of the MOOCs was adopted to study the effectiveness of computer graphics design, and found that the teaching of the digital learning model has significant benefits in terms of students' attitude towards learning and learning effectiveness, especially the "student satisfaction with teaching", the "improvement of abilities", and the "level of application" (Cheng \& Chen, 2016).

This study intends to explore the learning outcomes of learners using open educational resources with the TAM. The cognition and skills of learners were not included in this research because these cannot be achieved with open educational resources as the research subjects. Instead, this study explores learning outcomes as a reference for the curriculum design of open educational resources and the learning path of the learners. In this way, it should provide more diverse and better learning environments and content to enhance the quality of the course and the learning outcomes of the students.

\section{Research Framework and Methodology}

\section{Research Framework}

This study sets perceived convenience as the external variable of the TAM proposed by Davis in 1989. The participants' attitude and the behavioral intention towards using open educational resources were adopted as the indicators of to which degree they accept the technology. Moreover, learning outcome was used as perceived outcomes of the learners. The research framework of this study was showed in Figure 2.

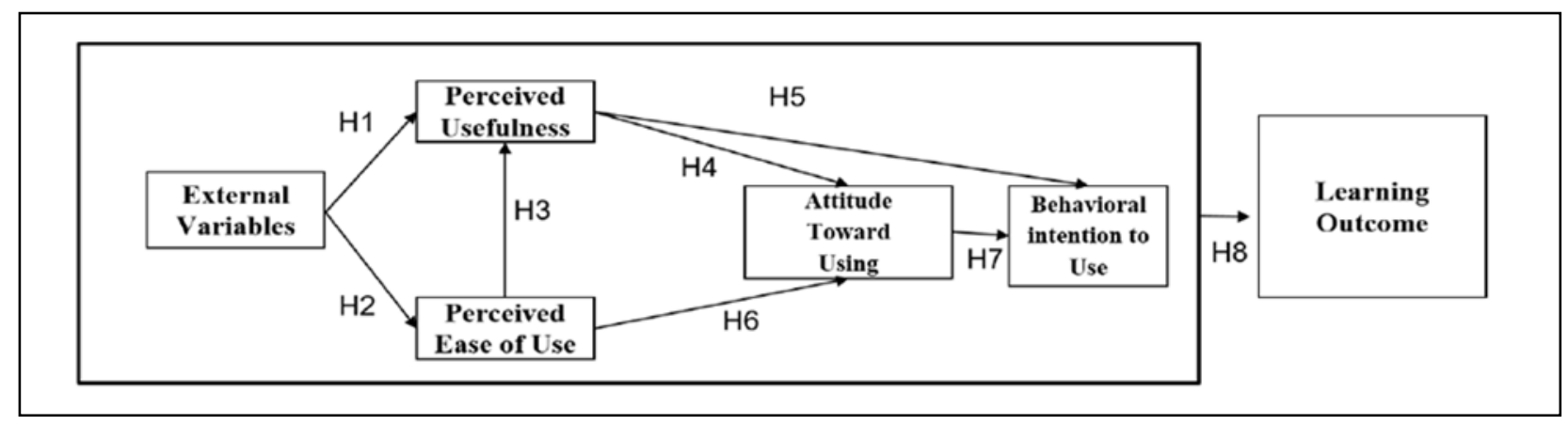

Figure 2. Research framework.

\section{Methodology}

This study is conducted mainly by questionnaire. After the literature review, the "Questionnaire on Learning Outcome of Open Educational Resources" is designed to collect data about the acceptance of the technology and learning outcome of using open educational resources. Purposive sampling was used to choose 
the participants who are to complete the questionnaire online. The collected data are examined by using the Partial Least Squares (PLS) statistical method.

Participants. In this study, open educational resources are defined as the courses of OCW and the MOOCs. The Questionnaire on Learning Outcome of Open Education Resources is designed for those who have used the resources. In total, 40 valid samples are collected, each of which is completed at least on online course from open educational resources.

Research tools. This study adopts a six-point Likert scale to collect the data of variables with one being "strongly disagree" while six being "strongly agree". The items for each variable were all designed by referring to the previous relevant researches. According to the situation of open educational resources, the items were revised so that they would be appropriate for this study. After revision, three experts were asked to help confirm whether the items for this study were properly expressed.

Perceived convenience is set as the external variable. There are five items for the variable, which are revised ones from the items designed by Yoon and Kim (2007). The items for the other four variables, namely perceived usefulness, perceived ease of use, attitude towards using, and behavioral intention to use, are all revised ones from the items by Davis (1989). There are four items for each variable, and there are 16 for these four variables. As for the learning outcome, the items for this variable are the revised ones of Cheng and Chen (2016) who designed the learning outcome scale. There are 10 items for the learning outcome. In total, the questionnaire has 30 items.

\section{Research Result}

\section{Partial Least Squares Analysis}

Measurement model analysis. As for the reliability of the items that constitute the questionnaire, the PLS analysis shows that the factor loadings of the 30 items range between 0.526 and 0.935 . Steenkamp and Van (1991) pointed out that a factor loading that exceeds 0.5 means a level of significance. Therefore, the 30 items all have high reliability.

As for the convergent validity of the six variables for the questionnaire, the values of their component reliability range between 0.835 and 0.954 . Formell and Larcker (1981) suggested that the component reliability exceed 0.7. Thus, the six variables have good internal consistency.

Moreover, the Average Variance Extracted (AVE) of the variables ranges between 0.565 and 0.802 . Fornell and Larcker (1981) suggested that the AVE exceed 0.5. Thus, the six variables have a high degree of convergence.

In addition, the AVE means for the six variables all exceed the coefficients between the variables. Fornell and Larcker (1981) advised that the square roots of the AVEs all exceed the coefficients of the variables. Therefore, the result indicates that the variables are of significant discriminant validity. Therefore, the structural model checking can be conducted.

Structural model analysis. The analytical results for this study are shown in Figure 3.

The following findings are revealed in Figure 3. (1) As for the relationship between perceived convenience and perceived ease of use, and that between perceived convenience and perceived usefulness, $t$ values both exceed 1.96 and $p$ values both are less than 0.001. (2) Perceived convenience exerts a positive impact on perceived ease of use, and the coefficient between the two is 0.587 . Similarly, perceived convenience has a positive impact on perceived usefulness, and the coefficient between the two is 0.475 . Evidently, the coefficient 
between perceived convenience and perceived ease of use exceeds that between perceived convenience and perceived usefulness. (3) As for the relationship between perceived ease of use and attitude toward using, $t$ is equal to 0.827 , which means that the $t$ value does not reach the level of significance. Therefore, the two variables are not positively correlated.

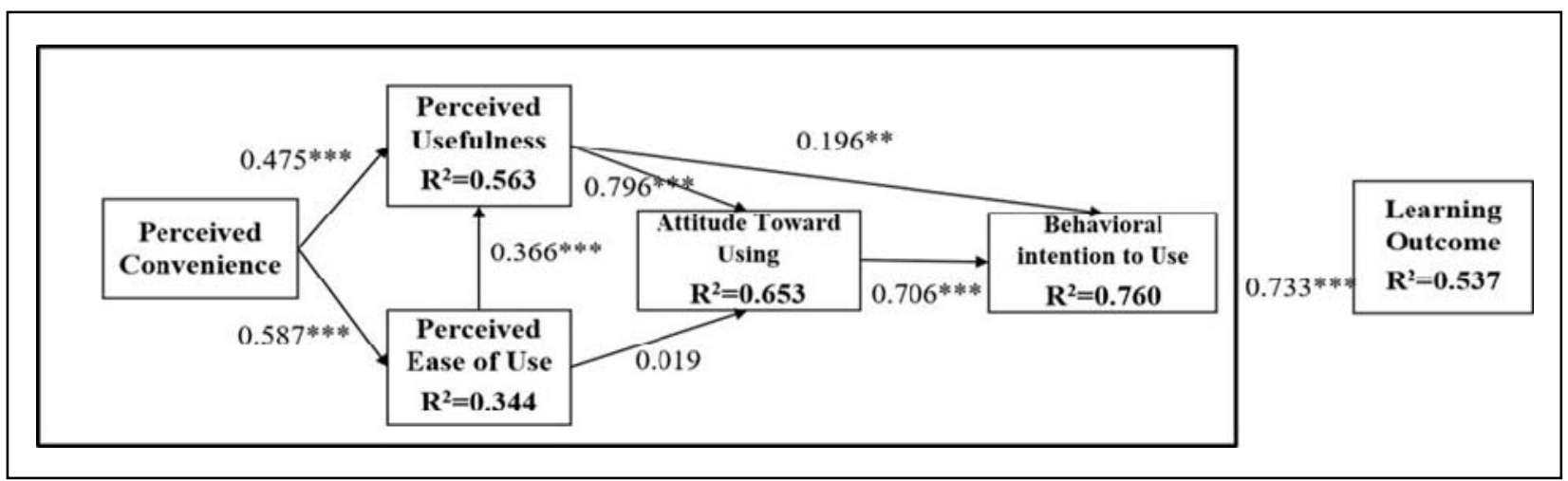

Figure 3. The analytical results for the structural model.

\section{Conclusion and Suggestion}

With rapid development of the Internet, it has become a dominant trend that learners are capable of learning without the limitations of time and space by taking open online courses. In this study, perceived convenience is set as the external variable for the TAM to predict and explain learners' acceptance of open educational resources. So far, there have been only a few researches into the acceptance and learning outcome of the open educational resources with the variable of perceived convenience. That is why this study is conducted.

After the research, the following findings are unveiled. First, the convenience of the access to online courses positively influences the use of open educational resources. This finding conforms to that of the research "A Study of Exploring Learners' Accepting Factors for Open E-learning Platform: The Case of Massive Open Online Course” by Ting (2015).

Second, scholars believe that the ease of operation of open educational resources have more significant impact than the improvement of learning outcomes. Moreover, the second finding is consistent with that of the research "The Research of Perceived Ease of Use, and Perceived Usefulness Moderating Social Influences on Electric Learning Efficiency” by Liao and Hsieh (2012).

Third, significant influence: The learners who used open educational resources care more about the practical help of the courses for their study and work, and less about whether the platform of the open educational resources is simple and easy to operate.

Therefore, the following suggestions are put forward for future researches.

Firstly, it is advised to enable learners to learn through mobile phone applications. If they can watch videos on their phone without accessing the website, which makes it more convenient to use the open educational resources, the ease of the use will be improved for users.

Secondly, great importance should be attached to the research and improvement of the ease of operation when relevant platforms are designed and developed to offer educational resources in the future.

Thirdly, it is recommended that open educational resources provide courses that are suitable for learners 
and with which they can conduct effective learning. In this way, learners will be willing to use open educational courses for self-directed learning.

\section{References}

Agarwal, R., \& Karahanna, E. (2000). Time flies when you're having fun: Cognitive absorption and beliefs about information technology usage. MIS Quarterly, 24(4), 665-694.

Alario-Hoyos, C., Estévez-Ayres, I., Pérez-Sanagustín, M., Kloos, C. D., \& Fernández-Panadero, C. (2017). Understanding learners' motivation and learning strategies in MOOCs. The International Review of Research in Open and Distributed Learning, 18(3), 120-137.

Baldwin, T. T., \& Ford, J. K. (1988). Transfer of training: A review and directions for future research. Personnel Psychology, 41(1), 63-105.

Bloom, B. S., \& Krathwohl, D. R. (1956). Taxonomy of educational objectives: The classification of educational goals. Handbook I: Cognitive domain. New York, NY: David McKay.

Burton-Jones, A., \& Hubona, G. S. (2006). The mediation of external variables in the technology acceptance model. Information \& Management, 43(6), 706-717.

Chang, T. S., \& Lin, C. S. (1981). Educational psychology. Taipei: Dong Hwa.

Cheng, R. L., \& Chen, T. Y. (2016). Exploring the influence of massive open online courses in computer-aided design and drafting courses. Taiwan Textile Research Journal, 26(3), 34-42.

Davis, F. D., Bagozzi, R. P., \& Warshaw, P. R. (1989). User acceptance of computer technology: A comparison of two theoretical models. Management Science, 35(8), 982-1003.

Fornell, C., \& Larcker, D. F. (1981). Evaluating structural equation models with unobservable variables and measurement error. Journal of Marketing Research, 6(1), 39-50.

Ho, R. G. (2013). From CAI to MOOC: Retrospect and prospect of E-learning in Taiwan. T\&D Glossary, 180, 1-28.

Hair, J. F., Black, B., Babin, B., Anderson, R. E., \& Tatham, R. L. (1992). Multivariate data analysis (6th ed.). New York, NY: Macmillan.

Henderson, R., \& Divett, M. J. (2003). Perceived usefulness, ease of use and electronic supermarket use. International Journal of Human-Computer Studies, 59(3), 383-395.

Hsiao, K. C. (2011). A study on the school-based curriculum development and pupils' learning outcomes on ceramic: A case study of the elementary school in Kaohsiung City (Master's thesis). Pingtung.

Hsu, C. N. (2017). A study on the relationship among students’ perceived ease of use, perceived usefulness, perceived playfulness, and perceived convenience toward Junyi Academy Platform and its impact on intention to use-An example of Gangshan Junior High School (Unpublished master's thesis, Shu-Te University, Taiwan, ROC).

Hsu, H. C., Ou-Yang, Y., \& Yin, M. C. (2016). A construction of self evaluation indicators on elementary school MOOCs curriculum design. Journal of Education, 36, 99-137.

Huang, T. H., Liu, Y. C., \& Yan, W. T. (2010). The effects on 6th grade students' mathematical achievement and learning motivation using innovative cooperative learning model with the aid of interactive whiteboard. Curriculum \& Instruction Quarterly, 14(1), 115-139.

Lee, M. M., Lin, M. F. G., \& Bonk, C. J. (2007). OOPS, Turning MIT Opencourseware into Chinese: An analysis of a community of practice of global translators. The International Review of Research in Open and Distributed Learning, 8(3).

Legris, P., Ingham, J., \& Collerette, P. (2003). Why do people use information technology? A critical review of the technology acceptance model. Information and Management, 40(3), 191-204.

Liao, P. W., \& Hsieh, J. Y. (2012). The research of perceived ease of use, and perceived usefulness moderating social influences on electric learning efficiency. International Journal on Digital Learning Technology, 4(2), 39-61.

Lin, J. Y., \& Liu, C. Y. (2013). The effect of personal innovativeness and perceived playfulness on smart phones users' attitude and behavior intention. Bulletin of National Pingtung Institute of Commerce, 15, 179-206.

Pai, F. Y., \& Huang, K. I. (2011). Applying the technology acceptance model to the introduction of healthcare information systems. Technological Forecasting and Social Change, 78(4), 650-660.

Peng, C. K. (2015). The promotion of active learning by open course ware-A case of a calculus course (Unpublished master's thesis, National Chung Hsing University, ROC). 
Sánchez, R. A., \& Hueros, A. D. (2010). Motivational factors that influence the acceptance of moodle using TAM. Computers in Human Behavior, 26(6), 1632-1640.

Steenkamp, J. B. E., \& Van, T. H. C. (1991). The use of lisrel in validating marketing constructs. International Journal of Research in Marketing, 8(4), 283-299.

Ting, P. F. (2015). A study of exploring learners' accepting factors for open E-learning platform: The case of massive open online course (Unpublished master's thesis, National Chung Hsing University, Taiwan, ROC).

Tough, A. (1982). Some major reasons for learning. Eric Document Reproduction Service No. ED 033251.

Yoon, C., \& Kim, S. (2007). Convenience and TAM in a ubiquitous computing environment: The case of wireless LAN. Electronic Commerce Research and Applications, 6(1), 102-112. 